\title{
Electrochemical Umpolung of Bromide: Transition-Metal-Free Bromination of Indole C-H Bond
}

\author{
Pan Zhang ${ }^{1}$, Jianbin Chen ${ }^{1, * \mathbb{C}}$, Wei Gao ${ }^{1}$, Yiting Xiao ${ }^{1}$, Changwei Liu ${ }^{2}$, Shanghui Xu ${ }^{1}$, \\ Xiaoli Yan ${ }^{1}$ and Dawei Qin ${ }^{1}$ \\ 1 Shandong Provincial Key Laboratory of Molecular Engineering, School of Chemistry and Pharmaceutical \\ Engineering, Qilu University of Technology (Shandong Academy of Sciences), Jinan 250353, China; \\ panzhang11@163.com (P.Z.); gaowei161212@163.com (W.G.); Olivia9802@163.com (Y.X.); \\ ShanghuiXu111@163.com (S.X.); xiaoliyan1a@163.com (X.Y.); qdw109@163.com (D.Q.) \\ 2 Faculty of Science and Forestry, University of Eastern Finland, 80101 Joensuu, Finland; changwl@uef.fi \\ * Correspondence: jchen@qlu.edu.cn
}

Received: 13 January 2019; Accepted: 12 February 2019; Published: 15 February 2019

\begin{abstract}
A facile and sustainable electrochemical umpolung of bromide ion protocol was developed under mild reaction conditions. Transition metal catalysts and exogenous chemical oxidants were obviated for the bromination of $\mathrm{C}-\mathrm{H}$ bond. Notably, graphite rod, which is commercially available at supermarkets and is inexpensive, was employed as the electrode material. This operationally easy and environmentally friendly approach accomplished the synthesis of 3-bromoindole in excellent yield and regioselectivity.
\end{abstract}

Keywords: umpolung; C-H functionalization; electrochemical organic synthesis; anodic oxidation; sustainable chemistry

\section{Introduction}

Umpolung or polarity inversion, one of the attractive techniques, is a fundamental concept that was first introduced by Seebach and Corey in the 1970s [1-3]. It has been widely used in organic synthesis as it can alter the reactivity of a specific functional group for a desirable reaction that would otherwise not be possible [4-19]. Under the concept, two nucleophiles can couple with each other (Scheme 1). Many functional groups, for instance, cyanides, N-heterocyclic carbenes (NHC), thiamine pyrophosphates (TPP) as well as dithiane moieties, have been treated as the mediators and/or catalysts for umpolung transformation [4-19].

$$
\mathrm{Nu}_{1}+\mathrm{Nu}_{2} \stackrel{\text { umpolung }}{\longrightarrow} \mathrm{Nu}_{1}-\mathrm{Nu}_{2}
$$

Scheme 1. Umpolung concept for coupling two nucleophiles.

Halogen ions, especially bromide ions, are typical nucleophiles, which are frequently used for nucleophilic substitution and addition. In order to achieve the umpolung of bromide to bromo-based electrophiles, strong chemical oxidants are regularly required [20-28]. However, based on the intrinsic disadvantages of chemical oxidants, such as toxicity, environmental pollution, explosion risk, and economic costs, there is a growing need for green and sustainable approaches for the umpolung of bromides. Electrochemistry represents one of the most sustainable ways because only clean electrons are involved in the process [29-48]. In line with this strategy, in 2015, Bell and Wang reported that bromide ion can be electro-oxidized with observation current and potential oscillations [49]. Xu et al. 
and $\mathrm{Yu}$ et al. described electrochemical oxidation of bromide on platinum electrodes in aqueous acidic solution and ionic liquid, respectively [50-52]. Some new materials have also been exploited as electrodes for the electro-oxidation of bromides [53,54]. Inspired by these elegant discoveries, we envisioned that umpolung of bromide can be achieved by electrochemical strategy.

Aromatic bromides are an important class of compounds, which are commonly utilized as the coupling partner in transition-metal-catalyzed cross-coupling reactions [55-67]. Thus, the development of a synthetic method of arylbromides has attracted tremendous efforts [68-82]. Among them, much progress has been made on palladium-catalyzed regioselective bromination of $\mathrm{C}-\mathrm{H}$ bonds using different agents. Sanford and co-workers elegantly delineated Pd-catalyzed C-H bromination of benzoquinoline with $N$-bromosuccinimide (NBS) as the brominating reagent [83-85]. Wan et al. and Jia et al. unraveled that copper halides can be treated as brominating agents in Pd-catalyzed bromination of arenes [86,87]. Notably, stoichiometric chemical oxidants are indispensable in the abovementioned $\mathrm{Pd}$-catalyzed $\mathrm{C}-\mathrm{H}$ bromination reactions. Moreover, electrophilic bromination of indoles has also been developed with sodium bromide $(\mathrm{NaBr})$ or potassium bromide $(\mathrm{KBr})$ as bromiding agents, which were mediated by strong chemical oxidants $[88,89]$. Interestingly, NBS was straightforwardly utilized for the electrophilic bromination under ultraviolet UV irradiation [90]. However, the high cost and the toxicity of chemical oxidants is associated with heavy pollution to the environment, making them a major concern for the synthetic industry. In order to overcome the disadvantages inherent in chemical oxidants, Kakiuchi and co-workers elegantly substantiated the Pd-catalyzed bromination of arylpyridine with hydrogen bromide via electrochemical oxidation [91]. Compared with regular palladium-catalyzed $\mathrm{C}-\mathrm{H}$ bromination, many advances were achieved for this electrochemical protocol. However, the involvement of corrosive acid $(\mathrm{HBr})$ and noble metal as the catalyst was the main drawback. Herein, we report on an electrochemical transition-metal-free $\mathrm{C}-\mathrm{H}$ bromination with bromide salts as the source under mild conditions with inexpensive electrode materials that are commercially available in supermarkets. [92]

\section{Results and Discussions}

To prove the concept, we chose ubiquitous bromide salts, i.e., tetrabutylammonium bromide $\left(n \mathrm{Bu}_{4} \mathrm{NBr}\right)$ and/or ammonium bromide $\left(\mathrm{NH}_{4} \mathrm{Br}\right)$, as the bromide source as well as the supporting electrolyte. In order to gain rational understanding of the oxidative process, cyclic voltammetric (CV) experiments were conducted. As shown in Figure 1 (dark red line), the oxidative peak potential of $\mathrm{Br}^{-}$ appeared at $0.96 \mathrm{~V}$ and $1.22 \mathrm{~V}$ versus $\mathrm{Ag} / \mathrm{Ag}^{+}$, which were assigned to the corresponding $\mathrm{Br} \cdot / \mathrm{Br}^{-}$ and $\mathrm{Br}^{+} / \mathrm{Br}$. redox couple, respectively [5-7]. Indole, one of the electron-rich heterocyclics, displayed a profound nucleophilicity, and its CV behavior was surveyed. Notably, the oxidative potential of indole was observed at $1.39 \mathrm{~V}$ versus $\mathrm{Ag} / \mathrm{Ag}^{+}$(Figure 1, bright red line). Intriguingly, both the peak potentials of $\mathrm{Br}^{-}$and indole unambiguously shifted and diminished to the positive side when equal molar of substrates were added. This scenario can be explained by the hydrogen bonding between the free $\mathrm{N}-\mathrm{H}$ moiety of indole and the bromide anion (Figure 1, blue line). Interestingly, the addition of equal molar of $\mathrm{NH}_{4} \mathrm{Br}$ to the mixture of $n \mathrm{Bu}_{4} \mathrm{NBr}$ and indole resulted in a recovery of the intrinsic peak potential (Figure 1, pink line). 


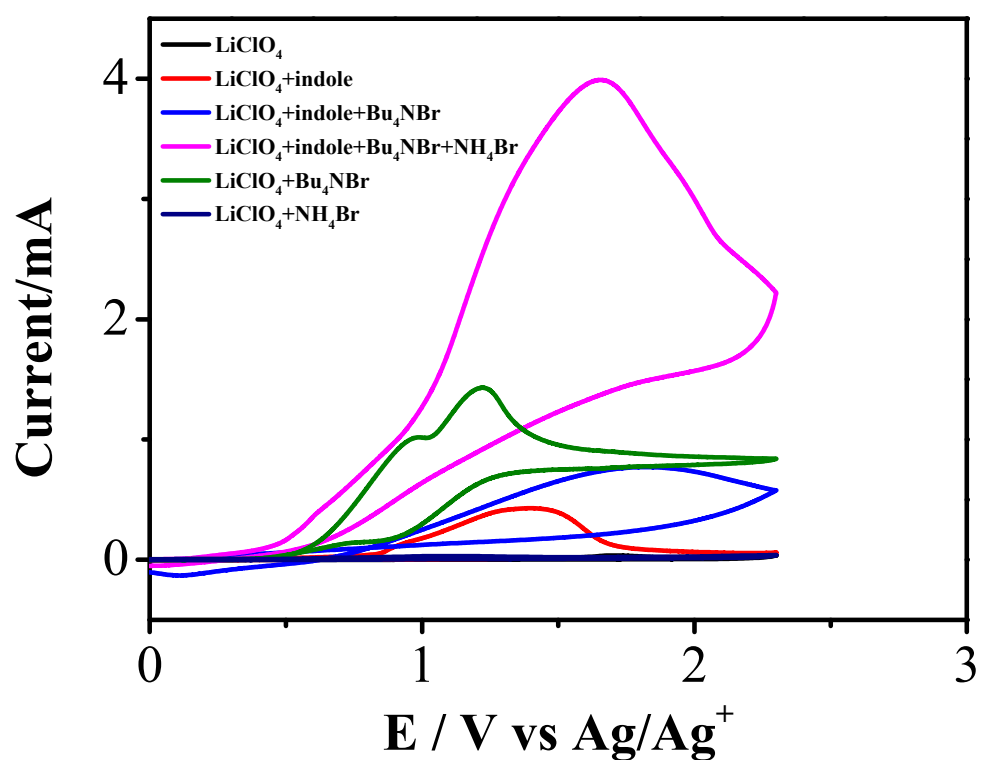

Figure 1. Cyclic voltammetry investigation of indole and bromide salts. Conditions: $\mathrm{LiClO}_{4}(0.1 \mathrm{M}$ in $\mathrm{MeCN}$ ) as background supporting electrolyte, glassy carbon as working electrode, $\mathrm{Pt}$ wire as counter electrode, $\mathrm{Ag}$ in $\mathrm{AgNO}_{3}(0.01 \mathrm{M})-\mathrm{LiClO}_{4}(0.1 \mathrm{M})$ in $\mathrm{MeCN}$ as reference electrode, indole $(0.1 \mathrm{M})$, $n \mathrm{Bu}_{4} \mathrm{NBr}(0.1 \mathrm{M})$, and $\mathrm{NH}_{4} \mathrm{Br}(0.1 \mathrm{M})$. The scan rate is $100 \mathrm{mV} / \mathrm{s}$.

With the aim of confirming the existence of hydrogen bonding, infrared (IR) spectroscopy of indole and/or bromide sources was further performed. As shown in Figure 2, the characteristic wavenumber (approximately $3370 \mathrm{~cm}^{-1}$ ) of free indole (free $\mathrm{N}-\mathrm{H}$ ) shifted distinctly to a new broad peak around $3200 \mathrm{~cm}^{-1}$ when equal molar of $n \mathrm{Bu}_{4} \mathrm{NBr}$ was added to the sample of indole. This phenomenon can again be attributed to the H-bonding interaction between the free $\mathrm{N}-\mathrm{H}$ and the bromide anion.

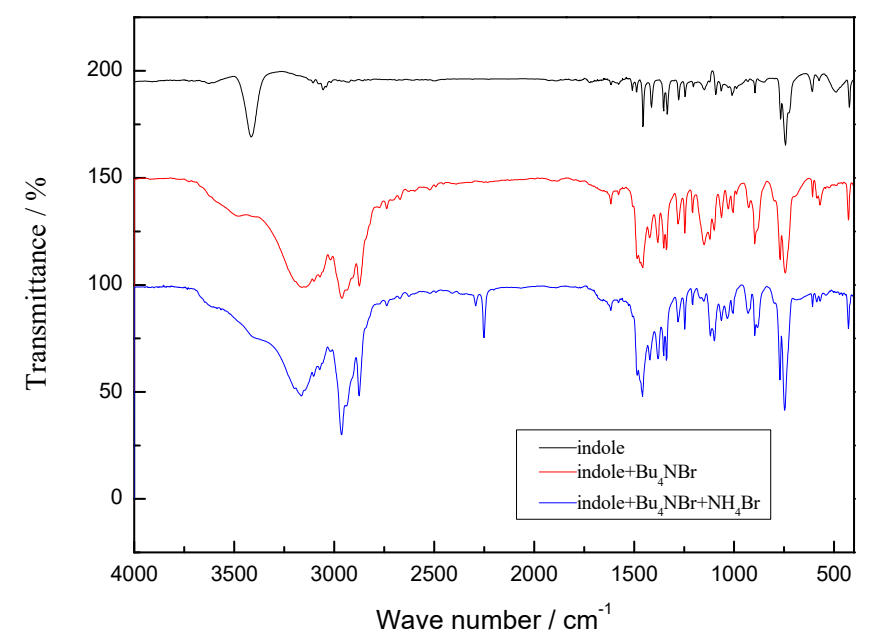

Figure 2. Infrared spectroscopy studies of indole and bromide salts.

With the understanding of electrochemical oxidative course, we carried out the reaction with indole 1 and $n \mathrm{Bu}_{4} \mathrm{NBr}$ as well as $\mathrm{NH}_{4} \mathrm{Br}$ to testify the electrochemical umpolung of bromide. Initially, the procedure employed the mixture of $n \mathrm{Bu}_{4} \mathrm{NBr}$ and $\mathrm{NH}_{4} \mathrm{Br}$ in order to interrupt the H-bonding with indole and was set up in 1,4-dioxane under a galvanostatic model. Unfortunately, trace of the desired product 2 was formed (Table 1, entry 1). However, when the reaction was run in tetrahydrofuran (THF), 39\% of 2 was generated (Table 1, entry 2). Chlorine-containing solvents, such as dichloroethane (DCE), provided moderate efficiency ( $43 \%$ yield, Table 1 , entry 3$)$. Then, we screened the aprotic polar 
media, for instance, dimethylforamide (DMF), dimethyl sulfoxide (DMSO), and ethyl acetate, in which $25 \%$ to $58 \%$ of the final product was isolated (Table 1, entries $4-6$ ). The ethanol as medium resulted in $20 \%$ yield (Table 1, entry 7 ). Satisfyingly, when the reaction was set up in acetonitrile (MeCN), excellent efficiency was observed ( $81 \%$ yield, Table 1, entry 8 ). Notably, this transformation was sensitive to water as the yield decreased sharply in the presence of water (Table 1, entry 11). Interestingly, this protocol worked smoothly when the amount of bromide salts was reduced, whereas no significant enhanced performance was detected when the quantity of bromide anion was increased (Table 1, entry 12 vs. 15). It should be noted that this approach almost shut down when only $\mathrm{NH}_{4} \mathrm{Br}$ was applied as the bromide source because of the poor solubility (Table 1, entry 16). In addition, diminished yield was observed with only $n \mathrm{Bu}_{4} \mathrm{NBr}$ as the nucleophile (Table 1, entry 17), presumably due to the slowdown in the cathodic reduction of proton to hydrogen. This was the case in the absence of $\mathrm{NH}_{4} \mathrm{Br}(\mathrm{Table} 1$, entries 9-10). Increasing or decreasing the current value and displacement of the graphite rod with platinum plate led to diminished yields.

Table 1. Reaction optimization. ${ }^{\text {a. }}$

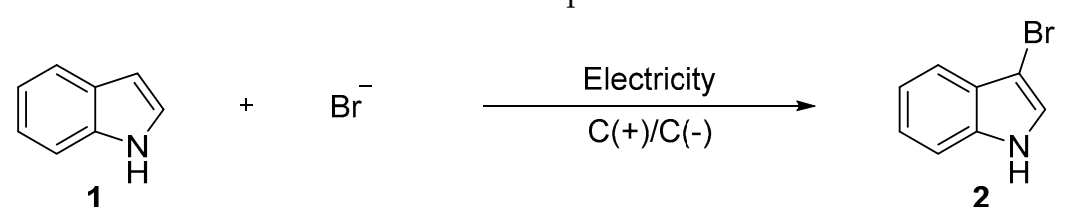

1

\begin{tabular}{|c|c|c|c|c|}
\hline Entry & Bromide Source & Solvent & Constant Current & Yield (\%) \\
\hline 1 & $\begin{array}{l}n \mathrm{Bu}_{4} \mathrm{NBr} / \mathrm{NH}_{4} \mathrm{Br} \\
\text { (2 equiv.-2 equiv.) }\end{array}$ & 1,4-dioxane & $2 \mathrm{~mA}$ & $<5$ \\
\hline 2 & $\begin{array}{l}n \mathrm{Bu}_{4} \mathrm{NBr} / \mathrm{NH}_{4} \mathrm{Br} \\
\text { (2 equiv.-2 equiv.) }\end{array}$ & THF & $2 \mathrm{~mA}$ & 39 \\
\hline 3 & $\begin{array}{l}n \mathrm{Bu}_{4} \mathrm{NBr} / \mathrm{NH}_{4} \mathrm{Br} \\
\text { (2 equiv.-2 equiv.) }\end{array}$ & DCE & $2 \mathrm{~mA}$ & 43 \\
\hline 4 & $\begin{array}{l}n \mathrm{Bu}_{4} \mathrm{NBr} / \mathrm{NH}_{4} \mathrm{Br} \\
\text { (2 equiv.-2 equiv.) }\end{array}$ & DMF & $2 \mathrm{~mA}$ & 25 \\
\hline 5 & $\begin{array}{l}n \mathrm{Bu}_{4} \mathrm{NBr} / \mathrm{NH}_{4} \mathrm{Br} \\
\text { (2 equiv.-2 equiv.) }\end{array}$ & DMSO & $2 \mathrm{~mA}$ & 54 \\
\hline 6 & $\begin{array}{l}n \mathrm{Bu}_{4} \mathrm{NBr} / \mathrm{NH}_{4} \mathrm{Br} \\
\text { (2 equiv.-2 equiv.) }\end{array}$ & EtOAc & $2 \mathrm{~mA}$ & 58 \\
\hline 7 & $\begin{array}{l}n \mathrm{Bu}_{4} \mathrm{NBr} / \mathrm{NH}_{4} \mathrm{Br} \\
(2 \text { equiv.-2 equiv.) }\end{array}$ & $\mathrm{EtOH}$ & $2 \mathrm{~mA}$ & 20 \\
\hline 8 & $\begin{array}{l}n \mathrm{Bu}_{4} \mathrm{NBr} / \mathrm{NH}_{4} \mathrm{Br} \\
\text { (2 equiv.-2 equiv.) }\end{array}$ & $\mathrm{MeCN}$ & $2 \mathrm{~mA}$ & 81 \\
\hline 9 & $\begin{array}{l}n \mathrm{Bu}_{4} \mathrm{NBr} / \mathrm{NaBr} \\
\text { (2 equiv.-2 equiv.) }\end{array}$ & $\mathrm{MeCN}$ & $2 \mathrm{~mA}$ & 60 \\
\hline 10 & $\begin{array}{c}n \mathrm{Bu}_{4} \mathrm{NBr} / \mathrm{KBr} \\
\text { (2 equiv.-2 equiv.) }\end{array}$ & $\mathrm{MeCN}$ & $2 \mathrm{~mA}$ & 28 \\
\hline 11 & $\begin{array}{l}n \mathrm{Bu}_{4} \mathrm{NBr} / \mathrm{NH}_{4} \mathrm{Br} \\
\text { (2 equiv.-2 equiv.) }\end{array}$ & $\begin{array}{l}\mathrm{MeCN} / \mathrm{H}_{2} \mathrm{O} \\
(10-2 \mathrm{~mL})\end{array}$ & $2 \mathrm{~mA}$ & 12 \\
\hline 12 & $\begin{array}{l}n \mathrm{Bu}_{4} \mathrm{NBr} / \mathrm{NH}_{4} \mathrm{Br} \\
\text { (1 equiv.- } 1 \text { equiv.) }\end{array}$ & $\mathrm{MeCN}$ & $2 \mathrm{~mA}$ & 80 \\
\hline 13 & $\begin{array}{l}n \mathrm{Bu}_{4} \mathrm{NBr} / \mathrm{NH}_{4} \mathrm{Br} \\
\text { (1 equiv.-1 equiv.) }\end{array}$ & $\mathrm{MeCN}$ & $2 \mathrm{~mA}$ & $62^{b}$ \\
\hline 14 & $\begin{array}{c}n \mathrm{Bu}_{4} \mathrm{NBr} / \mathrm{NH}_{4} \mathrm{Br} / \mathrm{NaBr} \\
(1-0.5-0.5 \text { equiv.) }\end{array}$ & $\mathrm{MeCN}$ & $2 \mathrm{~mA}$ & 64 \\
\hline 15 & $\begin{array}{l}n \mathrm{Bu}_{4} \mathrm{NBr} / \mathrm{NH}_{4} \mathrm{Br} \\
\text { (4 equiv.-2 equiv.) }\end{array}$ & $\mathrm{MeCN}$ & $2 \mathrm{~mA}$ & 82 \\
\hline 16 & $\mathrm{NH}_{4} \mathrm{Br}$ (2 equiv.) & $\mathrm{MeCN}$ & $2 \mathrm{~mA}$ & $<5$ \\
\hline 17 & $n \mathrm{Bu}_{4} \mathrm{NBr}$ (2 equiv.) & $\mathrm{MeCN}$ & $2 \mathrm{~mA}$ & 15 \\
\hline
\end{tabular}

a Reaction conditions: graphite rod anode and graphite rod cathode, indole $1(0.2 \mathrm{mmol})$, bromide salts as indicated, solvents $(10 \mathrm{~mL}), 2 \mathrm{~mA}$, air, $11.5 \mathrm{~h}$, room temperature. ${ }^{\mathrm{b}}$ under $\mathrm{O}_{2}$. 
Next, we focused our attention on the substrate scope. We tested a wide range of indole derivatives, as illustrated in Table 2. Good to excellent conversion of the corresponding starting materials was observed, as indicated by gas chromatography-mass spectrometry (GC-MS) and thin-layer chromatography (TLC). Surprisingly, we observed that most of the 3-bromoindole derivative products were not stable and decomposed quickly at ambient temperature of $28^{\circ} \mathrm{C}$. Furthermore, the titled products could only be stored for a few hours at $4{ }^{\circ} \mathrm{C}$ in the refrigerator.

Table 2. Testing of indole derivatives.

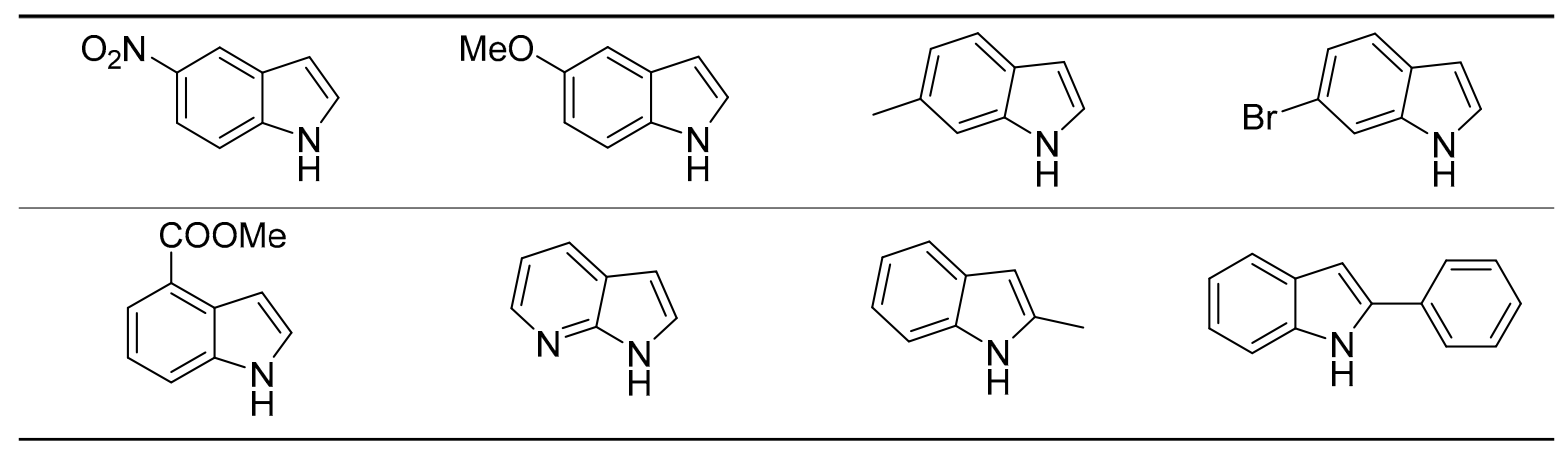

Based on the cyclic voltammetric analysis, a putative mechanism was proposed (Scheme 2). Consecutive anodic oxidation of bromide ion provided bromine cation to furnish the umpolung step. After nucleophilic addition of another nucleophile, indole accomplished the eventual product by releasing a proton. Cathodic evolution of hydrogen via reduction of proton served as the half-reaction.

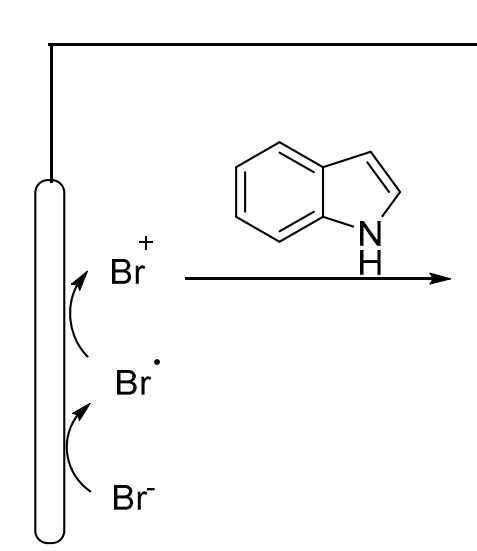

Graphite rod

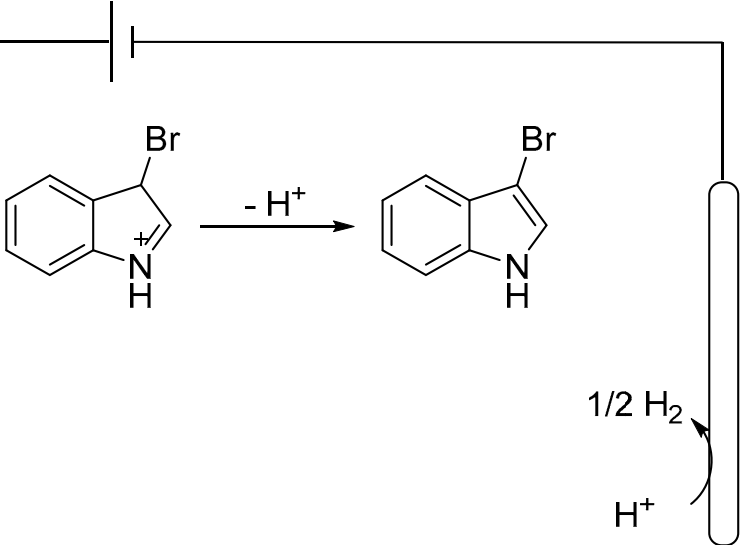

Graphite rod

Scheme 2. Proposed mechanism for the umpolung coupling of two nucleophiles.

\section{Experimental Section}

General Information: Chemicals and solvents were purchased from commercial suppliers and used as received. ${ }^{1} \mathrm{H}$ NMR and ${ }^{13} \mathrm{C}$ NMR spectra were recorded on a Bruker AVANCE II $400(400 \mathrm{MHz})$ spectrometer (Bruker, Switzerland). Chemical shifts were calibrated using residual undeuterated solvent as an internal reference $\left(\mathrm{CDCl}_{3}: 7.26 \mathrm{ppm}{ }^{1} \mathrm{H} \mathrm{NMR}, 77.0 \mathrm{ppm}{ }^{13} \mathrm{C} \mathrm{NMR}\right)$. The abbreviations used for explaining the multiplicity were as follows: $s=$ singlet, $d=$ doublet, $t=$ triplet, $q=$ quartet, $\mathrm{m}=$ multiplet, $\mathrm{dd}=$ doublet of doublet, brs = broad singlet. GC-MS spectra were recorded on Agilent 7890B-5977B (Agilent Technologies Inc., California, CA, USA). Both anode and cathode electrodes were carbon rod electrodes (diameter $1.0 \mathrm{~cm}$, length $10 \mathrm{~cm}$ ). TLC employed 0.25-mm glass silica gel plates. The developed chromatogram was analyzed by a UV lamp $(254 \mathrm{~nm})$. Flash chromatography columns were packed with $200-300$ mesh silica gel in petroleum (bp: $60-90^{\circ} \mathrm{C}$ ). Cyclic voltammograms were 
obtained on a CHI 760E potentiostat. IR spectra (CH Instruments Ins., Shanghai, China) were recorded on a Nicolet10 spectrometer (CH Instruments Ins., Shanghai, China).

General Procedure for the Electrolysis: An oven-dried, $10 \mathrm{~mL}$ two-neck glass flask was equipped with a magnetic stir bar. The substrate (0.20 mmol, 1 equiv.), $n \mathrm{Bu}_{4} \mathrm{NBr}(0.20-0.80 \mathrm{mmol}), \mathrm{NH}_{4} \mathrm{Br}$ (0.20-0.40 mmol), and $\mathrm{CH}_{3} \mathrm{CN}(10 \mathrm{~mL})$ were combined and added. The flask was equipped with carbon rod electrodes (diameter $1.0 \mathrm{~cm}$, length $10 \mathrm{~cm}$ ) as both the anode and the cathode. The reaction was initiated at a constant current of $2 \mathrm{~mA}$ at room temperature. After complete consumption of the starting material, the solvent was removed with a rotary evaporator. The residue was then subjected to flash column chromatography on silica gel to afford the product.

Cyclic Voltammetry Studies: Cyclic voltammetric measurements were carried out in a $50 \mathrm{~mL}$ glass vial at room temperature. A glassy carbon disk electrode (diameter is $3.0 \mathrm{~mm}$ ) was used as the working electrode, while a platinum plate electrode $\left(1.0 \times 1.0 \mathrm{~cm}^{2}\right)$ was used as counter electrode. The reference $\mathrm{Ag} / \mathrm{Ag}^{+}$electrode was made by immersing a sliver wire in a solution of $\mathrm{AgNO}_{3}$ $(0.01 \mathrm{M})-\mathrm{LiClO}_{4}(0.1 \mathrm{M})$ in $\mathrm{MeCN}$ and separated from the reaction by a salt bridge. The scan rate was $100 \mathrm{mV} / \mathrm{s}$.

Characterization of 3-Bromo-1H-indole: Column chromatography was used for purification on a silica gel column using petroleum ether:ethyl acetate $=10: 1$ as the eluent to give the product as a pale white solid. The data were consistent with the authentic sample. ${ }^{1} \mathrm{H}$ NMR (400 MHz, DMSO) $\delta 11.41$ $(\mathrm{s}, 1 \mathrm{H}), 7.48(\mathrm{~d}, J=2.7 \mathrm{~Hz}, 1 \mathrm{H}), 7.34-7.38(\mathrm{~m}, 2 \mathrm{H}), 7.10-7.14(\mathrm{~m}, 1 \mathrm{H}), 7.03-7.07(\mathrm{~m}, 1 \mathrm{H})$.

\section{Conclusions}

In summary, we developed a concise electrochemical umpolung of bromide ion under mild conditions. The electrolysis utilized cheap electrode material in undivided cell, providing 3-bromoindole in excellent yield.

Author Contributions: For research articles with several authors, a short paragraph specifying their individual contributions must be provided. The following statements should be used "conceptualization, J.C.; methodology, P.Z.; software, W.G.; validation, P.Z., W.G., Y.X. and C.L.; formal analysis, P.Z.; investigation, P.Z., W.G., S.X., X.Y.; resources, J.C.; data curation, D.Q.; writing-original draft preparation, P.Z., J.C., W.G.; writing-review and editing, J.C.; visualization, W.G.; supervision, J.C.; project administration, J.C.; funding acquisition, J.C.

Funding: This research was funded by Qilu University of Technology (Shandong Academy of Sciences), grant number No. 0412048811; Shandong Provincial Natural Science Foundation, grant number No. ZR2018BB017; National Natural Science Fundation of China, grant number No. 21801144, 81872744, 51602164. The APC was funded by No. 0412048811, No. ZR2018BB017, No. 21801144.

Acknowledgments: We greatly appreciate the financial support from the Qilu University of Technology (Shandong Academy of Sciences) (No. 0412048811), the Shandong Provincial Natural Science Foundation (No. ZR2018BB017), the National Natural Science Fundation of China (No. 21801144, 81872744, 51602164), and the Program for Scientific Research Innovation Team in Colleges and Universities of Shandong Province.

Conflicts of Interest: The authors declare no conflict of interest.

\section{References}

1. Seebach, D. Methods of Reactivity Umpolung. Angew. Chem. Int. Ed. 1979, 18, 239-258. [CrossRef]

2. Grobel, B.T.; Seebach, D. Umpolung of the Reactivity of Carbonyl Compounds Through Sulfur-containing Reagents. Synthesis 1977, 6, 357-402. [CrossRef]

3. Seebach, D.; Corey, E.J. Generation and Synthetic Applications of 2-lithio-1, 3-dithianes. J. Org. Chem. 1975, 40, 231-237. [CrossRef]

4. Hari, D.P.; Caramenti, P.; Waser, J. Cyclic Hypervalent Iodine Reagents: Enabling Tools for Bond Disconnection via Reactivity Umpolung. Acc. Chem. Res. 2018, 51, 3212-3225. [CrossRef] [PubMed]

5. Stephan, D.W. A Tale of Two Elements: The Lewis Acidity/Basicity Umpolung of Boron and Phosphorus. Angew. Chem. Int. Ed. 2017, 56, 5984-5992. [CrossRef] [PubMed]

6. Wang, M.H.; Scheidt, K.A. Cooperative Catalysis and Activation with N-Heterocyclic Carbenes. Angew. Chem. Int. Ed. 2016, 55, 14912-14922. [CrossRef] [PubMed] 
7. Liu, J.; Cao, C.G.; Sun, H.B.; Zhang, X.; Niu, D. Catalytic Asymmetric Umpolung Allylation of Imines. J. Am. Chem. Soc. 2016, 138, 13103-13106. [CrossRef] [PubMed]

8. Guo, C.; Fleige, M.; Janssen-Muller, D.; Daniliuc, C.G.; Glorius, F. Cooperative N-Heterocyclic Carbene/Palladium-Catalyzed Enantioselective Umpolung Annulations. J. Am. Chem. Soc. 2016, 138, 7840-7843. [CrossRef]

9. Waser, M.; Novacek, J. An Organocatalytic Biomimetic Strategy Paves the Way for the Asymmetric Umpolung of Imines. Angew. Chem. Int. Ed. 2015, 54, 14228-14231. [CrossRef] [PubMed]

10. Flanigan, D.M.; Romanov-Michailidis, F.; White, N.A.; Rovis, T. Organocatalytic Reactions Enabled by N-heterocyclic Carbenes. Chem. Rev. 2015, 115, 9307-9387. [CrossRef] [PubMed]

11. Yetra, S.R.; Patra, A.; Niju, A.T. Recent Advances in the N-heterocyclic Carbene (NHC)-organocatalyzed Stetter Reaction and Related Chemistry. Synthesis 2015, 47, 1357-1378. [CrossRef]

12. Evano, G.; Jouvin, K.; Theunissen, C.; Guissart, C.; Laouiti, A.; Tresse, C.; Heimburger, J.; Bouhoute, Y.; Veillard, R.; Lecomte, M. Turning Unreactive Copper Acetylides into Remarkably Powerful and Mild Alkyne Transfer Reagents by Oxidative Umpolung. Chem. Common. 2014, 50, 10008-10018. [CrossRef] [PubMed]

13. Cavitt, M.A.; Phun, L.H.; France, S. Intramolecular Donor-acceptor Cyclopropane Ring-opening Cyclizations. Chem. Soc. Rev. 2014, 43, 804-814. [CrossRef] [PubMed]

14. Nishi, T.; Mizota, I.; Shimizu, M. Integrated reactions using addition to conjugated imines and iminium salts. Pure Appl. Chem. 2012, 84, 2609-2617. [CrossRef]

15. Bugaut, X.; Glorius, F. Organocatalytic Umpolung: N-heterocyclic Carbenes and Beyond. Chem. Soc. Rev. 2012, 41, 3511-3522. [CrossRef] [PubMed]

16. Biju, A.T.; Kuhl, N.; Glorius, F. Extending NHC-catalysis: Coupling Aldehydes with Unconventional Reaction Partners. Acc. Chem. Res. 2011, 44, 1182-1195. [CrossRef]

17. Moeller, K.D. Intramolecular Anodic Olefin Coupling Reactions: Using Radical Cation Intermediates to Trigger New Umpolung Reactions. Synlett 2009, 8, 1208-1218. [CrossRef]

18. Guan, H. Titanium and Zirconium Mediated or Catalyzed Umpolung Reactions. Curr. Org. Chem. 2008, 12, 1406-1430. [CrossRef]

19. Smith, A.B.; Adam, C.M. Evolution of Dithiane-based Strategies for the Construction of Architecturally Complex Natural Products. Acc. Chem. Res. 2004, 37, 365-377. [CrossRef]

20. Wen, G.; Qiang, C.; Feng, Y.; Huang, T.; Ma, J. Bromate Formation During the Oxidation of Bromide-containing Water by Ozone/Peroxymonosulfate Process: Influencing Factors and Mechanisms. Chem. Eng. J. 2018, 352, 316-324. [CrossRef]

21. Tasi, K.Y.; Chang, I. Oxidation of Bromide to Bromine by Ruthenium (II) Bipyridine-Type Complexes Using the Flash-Quench Technique. Inorg. Chem. 2017, 56, 8497-8503.

22. Fang, J.; Zhao, Q.; Fan, C.; Shang, C.; Fu, Y.; Zhang, X. Bromate Formation from the Oxidation of Bromide in the UV/Chlorine Process with Low Pressure and Medium Pressure UV Lamps. Chemosphere 2017, 183, 582-588. [CrossRef] [PubMed]

23. Szel, V.; Cseko, G.; Horvath, A.K. Kinetics and Mechanism of the Oxidation of Bromide by Periodate in Aqueous Acidic Solution. J. Phys. Chem. A 2014, 118, 10713-10719. [CrossRef] [PubMed]

24. Pastoriza, C.; Antelo, J.M.; Crugeiras, J. Oxidation of Bromide by Tert-Butyl Hypochlorite. Int. J. Chem. Kinet. 2013, 45, 629-637. [CrossRef]

25. Sun, M.; Lowry, G.V.; Gregory, K.B. Selective Oxidation of Bromide in Waste Water Brines from Hydraulic Fracturing. Water Res. 2013, 47, 3723-3731. [CrossRef] [PubMed]

26. Lampre, I.; Marignier, J.-L.; Mirdamadi-Esfahani, M.; Pernot, P.; Archirel, P.; Mostafavi, M. Oxidation of Bromide Ions by Hydroxyl Radicals: Spectral Characterization of the Intermediate $\mathrm{BrOH}^{-}$. J. Phys. Chem. A 2013, 117, 877-887. [CrossRef] [PubMed]

27. Hung, M.; Bakac, A. Kinetics and Mechanism of Acid-catalyzed Oxidation of Bromide ions by the Aqueous Chromyl (IV) ion. Inorg. Chem. 2005, 44, 9293-9298. [CrossRef]

28. Marco, G.; Jens, H.; Koehler, F.; Spehar, K.; Kluge, R.; Csuk, R. Bromide-A New Method for the in situ Generation of Bromine and Its Application in the Synthesis of Functionalized Cyclic Ethers. Eur. J. Org. Chem. 2004, 18, 3799-3812.

29. Karkas, M.D. Electrochemical Strategies for C-H Functionalization and C-N Bond Formation. Chem. Soc. Rev. 2018, 47, 5786-5865. [CrossRef] 
30. Sauer, G.S.; Lin, S. An Electrocatalytic Approach to the Radical Difunctionalization of Alkenes. ACS Catal. 2018, 8, 5175-5187. [CrossRef]

31. Yang, Q.L.; Fang, P.; Mei, T.S. Recent Advances in Organic Electrochemical C-H Functionalization. Chin. J. Chem. 2018, 36, 338-352. [CrossRef]

32. Ma, C.; Fang, P.; Mei, T.-S. Recent Advances in C-H Functionalization Using Electrochemical Transition Metal Catalysis. ACS Catal. 2018, 8, 7179-7189. [CrossRef]

33. Sauermann, N.; Meyer, T.H.; Qiu, Y.; Ackermann, L. Electrocatalytic C-H Activation. ACS Catal. 2018, 8, 7086-7103. [CrossRef]

34. Tang, S.; Liu, Y.; Lei, A. Electrochemical Oxidative Cross-coupling with Hydrogen Evolution: A Green and Sustainable Way for Bond Formation. Chem. 2018, 4, 27-45. [CrossRef]

35. Chen, J.; Lv, S.; Tian, S. Electrochemical Transition-Metal-Catalyzed C-H Bond Functionalization: Electricity as Clean Surrogates of Chemical Oxidants. ChemSusChem 2019, 12, 115-132. [CrossRef] [PubMed]

36. Yan, M.; Kawamata, Y.; Baran, P.S. Synthetic Organic Electrochemical Methods since 2000: on the Verge of a Renaissance. Chem. Rev. 2017, 117, 13230-13319. [CrossRef] [PubMed]

37. Jiao, K.-J.; Zhao, C.-Q.; Fang, P.; Mei, T.-S. Palladium Catalyzed C-H Functionalization with Electrochemical Oxidation. Tetrahedron. Lett. 2017, 58, 797-802. [CrossRef]

38. Horn, E.J.; Rosen, B.R.; Baran, P.S. Synthetic Organic Electrochemistry: An Enabling and Innately Sustainable Method. ACS Cent. Sci. 2016, 2, 302-308. [CrossRef]

39. Waldvogel, S.R.; Mohle, S. Versatile Electrochemical C-H Amination via Zincke Intermediates. Angew. Chem. Int. Ed. 2015, 54, 6398-6399. [CrossRef]

40. Waldvogel, S.R.; Janza, B. Renaissance of Electrosynthetic Methods for the Construction of Complex Molecules. Angew. Chem. Int. Ed. 2014, 53, 7122-7123. [CrossRef]

41. Francke, R.; Little, R.D. Redox Catalysis in Organic Electrosynthesis: Basic Principles and Recent Developments. Chem. Soc. Rev. 2014, 43, 2492-2521. [CrossRef] [PubMed]

42. Frontana-Uribe, B.A.; Little, R.D.; Ibanez, J.G.; Palma, A.; Vasquez-Medrano, R. Organic Electrosynthesis: a Promising Green Methodology in Organic Chemistry. Green. Chem. 2010, 12, 2099-2119. [CrossRef]

43. Yoshida, J.-I.; Kataoka, K.; Horcajada, R.; Nagaki, A. Modern Strategies in Electroorganic Synthesis. Chem. Rev. 2008, 108, 2265-2299. [CrossRef] [PubMed]

44. Savéan, J.-M. Molecular Catalysis of Electrochemical Reactions. Mechanistic Aspects. Chem. Rev. 2008, 108, 2348-2378.

45. Jutand, A. Contribution of Electrochemistry to Organometallic Catalysis. Chem. Rev. 2008, 108, $2300-2347$. [CrossRef] [PubMed]

46. Geiger, W.E. Organometallic Electrochemistry: Origins, Development, and Future. Organometallics 2007, 26, 5738-5765. [CrossRef]

47. Sperry, J.B.; Wright, D.L. The Application of Cathodic Reductions and Anodic Oxidations in the Synthesis of Complex Molecules. Chem. Soc. Rev. 2006, 35, 605-621. [CrossRef]

48. Moeller, K.D. Synthetic Applications of Anodic Electrochemistry. Tetrahedron 2000, 56, 9527-9554. [CrossRef]

49. Bell, J.G.; Wang, J. Current and Potential Oscillations During the Electro-oxidation of Bromide ions. J. Electroanal. Chem. 2015, 754, 133-137. [CrossRef]

50. Xu, J.; Georgescu, N.S.; Scherson, D.A. The Oxidation of Bromide on Platinum Electrodes in Aqueous Acidic Solutions: Electrochemical and In Situ Spectroscopic Studies. J. Electrochem. Soc. 2014, 161, H392-H398. [CrossRef]

51. Yu, L.; Jin, X.; Chen, G.Z. A Comparative Study of Anodic Oxidation of Bromide and Chloride ions on Platinum Electrodes in 1-Butyl-3-methylimidazolium Hexafluorophosphate. J. Electroanal. Chem. 2013, 688, 371-378. [CrossRef]

52. Allen, G.D.; Buzzeo, M.C.; Villagran, C.; Hardacre, C.; Compton, R.G. A Mechanistic Study of the Electro-oxidation of Bromide in Acetonitrile and the Room Temperature Ionic Liquid, 1-Butyl-3-methylimidazolium Bis(trifluoromethylsulfonyl)imide at Platinum Electrodes. J. Electroanal. Chem. 2005, 575, 311-320. [CrossRef]

53. Katayama, Y.; Koshizawa, S.; Mirua, T. Photoassisted Anodic Oxidation of Bromide on an n-Type Titanium Dioxide Electrode in an Amide-Type Ionic Liquid. ECS Trans. 2010, 33, 503-507.

54. Krivenko, A.G.; Komarova, N.S.; Ryabenko, A.G. Sul'yanov, S.N. Debundling of Carbon Single-walled Nanotubes at Oxidation of Bromine ions. Electrochem. Commun. 2010, 12, 1049-1051. [CrossRef] 
55. Dong, Z.; Lu, G.; Wang, J.; Liu, P.; Dong, G. Modular ipso/ortho Difunctionalization of Aryl Bromides via Palladium/Norbornene Cooperative Catalysis. J. Am. Chem. Soc. 2018, 140, 8551-8562. [CrossRef] [PubMed]

56. Hazari, N.; Melvin, P.R.; Beromi, M.M. Well-defined Nickel and Palladium Precatalysts for Cross-coupling. Nat. Rev. Chem. 2017, 1, 0025. [CrossRef] [PubMed]

57. He, J.; Wasa, M.; Chan, K.S.L.; Shao, Q.; Yu, J.-Q. Palladium-catalyzed Transformations of Alkyl C-H bonds. Chem. Rev. 2017, 117, 8754-8786. [CrossRef]

58. Monrose, A.; Salembier, H.; Bousquet, T.; Pellegrini, S.; Pélinski, L. Diethyloxalate as “CO” Source for Palladium-Catalyzed Ethoxycarbonylation of Bromo-and Chloroarene Derivatives. Adv. Synth. Catal. 2017, 359, 2699-2704. [CrossRef]

59. Zhu, F.; Rourke, M.J.; Yang, T.; Rodriguez, J.; Walczak, M.A. Highly Stereospecific Cross-coupling Reactions of Anomeric Stannanes for the Synthesis of C-aryl Glycosides. J. Am. Chem. Soc. 2016, 138, 12049-12052. [CrossRef]

60. Chen, J.; Natte, K.; Spannenberg, A.; Neumann, H.; Langer, P.; Beller, M.; Wu, X.F. Base-Controlled Selectivity in the Synthesis of Linear and Angular Fused Quinazolinones by a Palladium-Catalyzed Carbonylation/Nucleophilic Aromatic Substitution Sequence. Angew. Chem. Int. Ed. 2014, 53, 7579-7583. [CrossRef]

61. Chen, J.; Natte, K.; Neumann, H.; Wu, X.-F. Palladium-Catalyzed Carbonylative Reactions of 1-Bromo-2-fluorobenzenes with Various Nucleophiles: Effective Combination of Carbonylation and Nucleophilic Substitution. Chem. Eur. J. 2014, 20, 16107-16110. [CrossRef] [PubMed]

62. Chen, J.; Natte, K.; Spannenberg, A.; Neumann, H.; Beller, M.; Wu, X.-F. Efficient Palladium-catalyzed Double Carbonylation of o-dibromobenzenes: Synthesis of Thalidomide. Org. Biomol. Chem. 2014, 12, 5578-5581. [CrossRef]

63. Anbarasan, P.; Schareina, T.; Beller, M. Recent Developments and Perspectives in Palladium-catalyzed Cyanation of Aryl halides: Synthesis of Benzonitriles. Chem. Soc. Rev. 2011, 40, 5049-5067. [CrossRef] [PubMed]

64. Zhang, G.; Ren, X.; Chen, J.; Hu, M.; Cheng, J. Copper-mediated Cyanation of Aryl Halide with the Combined Cyanide Source. Org. Lett. 2011, 13, 5004-5007. [CrossRef]

65. Schareina, T.; Zapf, A.; Cotte, A.; Gotta, M.; Beller, M. A Versatile Protocol for Copper-Catalyzed Cyanation of Aryl and Heteroaryl Bromides with Acetone Cyanohydrin. Adv. Synth. Catal. 2011, 353, 777-780. [CrossRef]

66. Schade, M.A.; Metzger, A.; Hug, S.; Knochel, P. Nickel-catalyzed Cross-coupling Reactions of Benzylic Zinc Reagents with Aromatic Bromides, Chlorides and Tosylates. Chem. Commun. 2008, 3046-3048. [CrossRef] [PubMed]

67. Hartwig, J.F. Evolution of a Fourth Generation Catalyst for the Amination and Thioetherification of Aryl Halides. Acc. Chem. Res. 2008, 41, 1534-1544. [CrossRef]

68. Gao, S.; Bethel, T.K.; Kakeshpour, T.; Hubbell, G.E.; Jackson, J.E.; Tepe, J.J. Substrate Controlled Regioselective Bromination of Acylated Pyrroles Using Tetrabutylammonium Tribromide ( $\mathrm{TBABr}_{3}$ ). J. Org. Chem. 2018, 83, 9250-9255. [CrossRef]

69. Moriuchi, T.; Fukui, Y.; Sakuramoto, T.; Hirao, T. Oxidative Bromination Reactions in Aqueous Media by Using $\mathrm{Bu}_{4} \mathrm{NBr} / \mathrm{TFA} / \mathrm{H}_{2} \mathrm{O}_{2}$ System. Chem. Lett. 2017, 46, 1708-1710. [CrossRef]

70. Voskressensky, L.G.; Golantsov, N.E.; Maharramov, A.M. Recent Advances in Bromination of Aromatic and Heteroaromatic Compounds. Synthesis 2016, 48, 615-643. [CrossRef]

71. Khan, A.H.; Chen, J.S. Synthesis of Breitfussin B by Late-stage Bromination. Org. Lett. 2015, 17, 3718-3721. [CrossRef] [PubMed]

72. Xu, T.; Zhou, W.; Wang, J.; Li, X.; Gao, J.-W.; Wang, B. A Mild Method for the Regioselective Bromination of 2-Aminopyridines. Tetrahedron Lett. 2014, 55, 5058-5061. [CrossRef]

73. Li, H.-J.; Wu, Y.-C.; Dai, J.-H.; Song, Y.; Cheng, R.; Qiao, Y. Regioselective Electrophilic Aromatic Bromination: Theoretical Analysis and Experimental Verification. Molecules 2014, 19, 3401-3416. [CrossRef] [PubMed]

74. Liu, C.; Dai, R.; Yao, G.; Deng, Y. Selective Bromination of Pyrrole Derivatives, Carbazole and Aromatic Amines with DMSO/HBr under Mild Conditions. J. Chem. Res. 2014, 38, 577-638. [CrossRef]

75. Thapa, R.; Brown, J.; Balestri, T.; Taylor, R.T. Regioselectivity in free Radical Bromination of Unsymmetrical Dimethylated Pyridines. Tetrahedron Lett. 2014, 55, 6743-6746. [CrossRef]

76. Rayala, R.; Wnuk, S.F. Bromination at C-5 of Pyrimidine and C-8 of Purine Nucleosides with 1, 3-Dibromo-5, 5-dimethylhydantoin. Tetrahedron Lett. 2012, 53, 3333-3336. [CrossRef] [PubMed] 
77. Cristiano, R.; Walls, A.D.; Weiss, R.G. Sequential Bromination Reactions from Beads with Methyltriphenylphosphonium Tribromide Groups. J. Phy. Org. Chem. 2010, 23, 904-909. [CrossRef]

78. Roya, S.; Bhar, S. Sodium Tungstate-catalyzed “On-water" Synthesis of $\beta$-arylvinyl Bromides. Green Chem. Lett. Rev. 2010, 3, 341-347. [CrossRef]

79. Schlosser, M.; Mongin, F. Pyridine Elaboration Through Organometallic Intermediates: Regiochemical Control and Completeness. Chem. Soc. Rev. 2007, 36, 1161-1172. [CrossRef]

80. Mortier, J.; Moyroud, J.; Bennetau, B.; Cain, P.A. The Carboxylic Acid Group as an Effective Director of ortho-lithiation. J. Org. Chem. 1994, 59, 4042-4044. [CrossRef]

81. Parham, W.E.; Bradsher, C.K. Aromatic Organolithium Reagents Bearing Electrophilic Groups. Preparation by Halogen-lithium Exchange. Acc. Chem. Res. 1982, 15, 300-305. [CrossRef]

82. Petrone, D.A.; Ye, J.; Lautens, M. Modern Transition-Metal-Catalyzed Carbon-Halogen Bond Formation. Chem. Rev. 2016, 116, 8003-8104. [CrossRef] [PubMed]

83. Dick, A.R.; Hull, K.L.; Sanford, M.S. A Highly Selective Catalytic Method for the Oxidative Functionalization of C- H Bonds. J Am Chem Soc. 2004, 126, 2300-2301. [CrossRef] [PubMed]

84. Kalyani, D.; Dick, A.R.; Anani, W.Q.; Sanford, M.S. A Simple Catalytic Method for the Regioselective Halogenation of Arenes. Org Lett. 2006, 8, 2523-2526. [CrossRef] [PubMed]

85. Kalyani, D.; Dick, A.R.; Anani, W.Q.; Sanford, M.S. Scope and Selectivity in Palladium-Catalyzed Directed C-H Bond Halogenation Reactions. Tetrahedron. 2006, 62, 11483-11498. [CrossRef]

86. Wan, X.; Ma, Z.; Li, B.; Zhang, K.; Cao, S.; Zhang, S.; Shi, Z. Highly Selective C- H Functionalization/Halogenation of Acetanilide. J. Am. Chem. Soc. 2006, 128, 7416-7417. [CrossRef] [PubMed]

87. Jia, X.; Yang, D.; Wang, W.; Luo, F. Chelation-Assisted Palladium-Catalyzed Cascade Bromination/Cyanation Reaction of 2-Arylpyridine and 1-Arylpyrazole C- H Bonds. J. Cheng, J. Org. Chem. 2009, 74, 9470-9474. [CrossRef]

88. Himabindu, V.; Parvathaneni, S.P.; Rao, V.J. PhI (OAc) $)_{2} / \mathrm{NaX}-$ Mediated Halogenation Providing Access to Valuable Synthons 3-Haloindole Derivatives. New. J. Chem. 2018, 42, 18889-18893. [CrossRef]

89. Khazaei, A.; Zolfigol, M.A.; Kolvari, E.; Koukabi, N.; Soltni, H.; Komaki, F. Electrophilic Bromination of Alkenes, Alkynes, and Aromatic Amines with Potassium Bromide/Orthoperiodic Acid under Mild Conditions. Synthesis 2009, 21, 3672-3676. [CrossRef]

90. Chhattise, P.K.; Ramaswamy, A.V.; Waghmode, S.B. Regioselective, Photochemical Bromination of Aromatic Compounds Using N-bromosuccinimide. Tetrahedron Lett. 2008, 49, 189-194. [CrossRef]

91. Kakiuchi, F.; Kochi, T.; Mutsutani, H.; Kobayashi, N.; Urano, S.; Sato, M.; Nishiyama, S.; Tanabe, T. Palladium-Catalyzed Aromatic C-H Halogenation with Hydrogen Halides by Means of Electrochemical Oxidation. J. Am. Chem. Soc. 2009, 131, 11310-11311. [CrossRef] [PubMed]

92. Sun, L.; Zhang, X.; Li, Z.; Ma, J.; Zeng, Z.; Jiang, H. A Versatile C-H Halogenation Strategy for Indole Derivatives under Electrochemical Catalyst- and Oxidant-free Condition. Eur. J. Org. Chem. 2018, 35, 4949-4952. [CrossRef]

Sample Availability: Samples of the compounds "3-bromoindole" are available from the authors.

(C) 2019 by the authors. Licensee MDPI, Basel, Switzerland. This article is an open access article distributed under the terms and conditions of the Creative Commons Attribution (CC BY) license (http://creativecommons.org/licenses/by/4.0/). 